\title{
Desordens neurais do desenvolvimento: perspectivas de abor- dagem e suas implicações para a educação e a reabilitação
}

\author{
Maria Luísa Bissoto*
}

\section{Resumo}

Esse artigo discute as desordens neurais de desenvolvimento, principalmente aquelas de etiologia genética, com o objetivo de analisar diferentes perspectivas teóricas sobre o desenvolvimento humano, pré e pós-natal, a estas subjacentes, e seu impacto no entendimento de quem é o sujeito portador desse tipo de desordem. Metodologicamente, são comparados pressupostos epistemológicos referentes a abordagens neuropsicológicas "clássicas" e "neuroconstrutivistas". Como resultados decorrentes desta análise comparativa, foram considerados pressupostos relevantes, para o objetivo referido: a) o papel atribuído à circunstancialidade do sujeito; b) a questão da plasticidade e dinamicidade do desenvolvimento e c) a forma como se encaminha o desenvolvimento do sistema nervoso e do indivíduo, do período pré-natal ao período pósnatal. As considerações finais argumentam que as abordagens de caráter neuroconstrutivistas permitem conceber o desenvolvimento do portador de desordens neurais de etiologia genética não como "falta", mas como todo um processo diferenciado e particular de desenvolvimento. Este processo precisa ser compreendido, ao menos nos meios educacionais e de reabilitação, não como uma categoria nosológica, mas na especificidade de um sujeito, que se põe-no-mundo buscando engajar-se nesse.

Palavras-chave: desordens neurais; desenvolvimento humano; educação e reabilitação.

\section{Neurodevelopmental disorders: theoretical approaches and its implications for education and rehabilitation}

\section{Abstract}

The neurodevelopmental disorders, mainly those genetics ones, are argued with the aim to analyze the human development conceptions that underlie these, and its impact for understanding who is the individual that carries this disorder. Methodologically, epistemological presupposition from "classical" neuropsychology and from "neuroconstructivist" neuropsychology had been compared. As results of this parallel had been considered relevant: a. the role of the individual surrounding, $b$. the question concerning the plasticity and dynamical character of development and c. the form of the brain development and individu-

\footnotetext{
* Professora doutora do Centro Universitário Salesiano de São Paulo. Americana, São Paulo, Brasil.
} 
al developmental process, from prenatal to postnatal period. The concluding comments claims that the Neuroconstructivist approaches allow conceiving the developmental process within genetics neurodevelopmental disorders not as a "fault" but as a differentiated and particular one. That should be understood in the Educational and Rehabilitation settings not as a nosological category but as a specific way of an individual acting while looking for a mode of being-in-theworld.

Keywords: neurodevelopmental disordes; human development; education e rehabilitation.

\section{Introdução}

As desordens neurais do desenvolvimento podem ser definidas como aquelas que alteram, de maneira substancial e persistente, o desenvolvimento normalmente esperado do sistema nervoso; quer suas manifestações se apresentem intra-uterinamente, ao nascimento, ou em períodos etários subsequentes (INSEL, 2009). Essas manifestações revelam limitações, com graus variados de severidade, em múltiplos domínios da vida cotidiana, estando especialmente afetados a cognição, a motricidade, a visão e a audição, a produção e compreensão da linguagem, a emotividade, a socialização e o comportamento. A extensão dos danos ao sistema nervoso pode levar, ainda, a maior suscetibilidade no desenvolvimento de comorbidades. Embora a maioria das desordens neurais de desenvolvimento não tenha seus mecanismos etiológicos especificamente conhecidos e individuados, pode-se considerar que essas são relacionadas a dois grandes grupos de fatores: endógenos (alterações genéticas e metabólicas, por exemplo) e exógenos, abrangendo fatores diversos como traumas, doenças infecciosas, exposição a toxinas, drogas, privação severa de contato afetivo, de nutrição ou de estimulação, dentre outros.

No caso das desordens neurais de desenvolvimento de etiologia genética, especialmente consideradas nesse artigo, estão presentes alterações em funções geneticamente influenciadas, ocasionando: a) erros ou disfunções no metabolismo, impedindo ou tornando deficiente a produção de elementos essenciais ao funcionamento neuronal (ex: fenilcetonúria); b) um mau funcionamento ou uma má formação do tecido cerebral, com correlatas anormalidades estruturais no sistema nervoso, mas também podendo comprometer outros sistemas (ex: esclerose tuberosa, neurofibromatose) ou c) modificações cromossômicas, provocando impactos diversos no desenvolvimento neuropsicomotor (ex: Síndrome de Down, X-Frágil, Síndrome de Prader-Willi) (HUNTERDON DEVELOPMENTAL CENTER, 2009).

D. Cicchetti (2006) propõe um modelo multinível de entendimento das desordens neurais de desenvolvimento, interagindo de maneira imbricada: um primeiro nível, denominado de etiológico, abordando as influências que predispo- 
riam o indivíduo a um maior risco de psicopatologias; um segundo nível, aquele dos mecanismos cerebrais sobre os quais esses fatores de risco atuariam; o terceiro nível, atribuído aos processos neuropsicológicos, que estariam afetados pela influência dos dois níveis descritos e um quarto nível, relativo aos comportamentos ou fenótipos comportamentais, resultante de todos os níveis anteriores. A ideia central subjacente à proposição desse modelo é a de que o último nível, aquele da exteriorização das desordens via um comportamento atípico, não pode ser, de forma reducionista, atribuído a um único fator causal. Deve, antes, ser entendido como decorrente da interação, difícil de identificar e prever, de todos os demais níveis, exigindo uma complexidade nas formas de abordagem.

Outra categorização das desordens neurais pode ser encontrada em M. Thomas (2009) relacionando-as a desordens neurais de desenvolvimento etiologicamente ligadas a anormalidades já geneticamente reconhecidas, definidas pelo déficit comportamental (TDAH, autismo, por exemplo), de etiologia desconhecida e causadas por fatores ambientais.

Impactando cronicamente a funcionalidade dos indivíduos afetados e abrangendo quadros diversos como patologias degenerativas do sistema nervoso, síndromes cromossômicas e metabólicas, patologias psiquiátricas de etiologia neurológica, transtornos de hiperatividade e desordens relacionadas ao espectro autístico, estima-se que as desordens neurais de desenvolvimento afetem um bilhão e meio de pessoas, no mundo todo (IOM, 2001).

As consequências individuais, familiares e sociais das desordens neurais de desenvolvimento são profundas. O comprometimento das funções cognitivas, psíquicas, motoras, sensoriais, comportamentais e linguísticas acarreta grande estigmatização e limitação na "encorporação" dos códigos socioculturais existentes em uma coletividade, afetando em muito a qualidade de vida dos portadores.

As desordens neurais de desenvolvimento estão, assim, entre aquelas que requerem ações complexas por parte de uma sociedade, tanto no que se refere à prevenção das mesmas quanto no que se refere à atenção aos casos já existentes. São ações que envolvem setores de saúde pública, de educação e de reabilitação, de seguridade social, de infraestrutura básica e arquitetônica, de possibilidade de geração de renda e de acesso a bens materiais, culturais e de serviços, dentre outros. Inscrevem-se também nas discussões da Bioética, principalmente ao considerar-se seu caráter genético. O campo da educação e aquele da reabilitação, pelo seu duplo viés preventivo-interventivo, e também por se caracterizarem pelo acompanhamento do indivíduo no seu processo de desenvolvimento ao longo do ciclo vital, mostram-se especialmente importantes.

E, contudo, são campos que se revelam consideravelmente estáticos naquilo que se refere às bases epistemológicas de compreensão do sujeito de 
um diagnóstico de desordens neurais de desenvolvimento. Por afetarem esse sujeito, muitas vezes embrionariamente, tais desordens parecem assumir, no senso comum do cotidiano educacional/reabilitador, a figura de um curso de desenvolvimento já previamente marcado. Ideia que pode ser reforçada: pelos comportamentos - muitas vezes disruptivos e/ou de difícil modificação - que coexistem às desordens e pelos paradigmas dominantes nas áreas médica/ neuropsicológica de entendimento do desenvolvimento do sistema nervoso e, concomitantemente, da forma de agir sobre esse. As desordens neurais de desenvolvimento de etiologia genética são ainda mais penalizadas, seguindo a assunção, que se revela bastante entranhada no pensamento científico (ou pseudocientífico), de que a inscrição genética se encontra correspondentemente um caráter de verdade, em relação às possibilidades de desenvolvimento do indivíduo.

Tradicionalmente, a perspectiva neuropsicológica clássica, que se apoia na assunção de que os comportamentos inadaptados se encontram subjacentes anormalidades estruturais específicas e pontuais no sistema nervoso, tem dominado as práticas educacionais e de reabilitação. Avanços científicos das últimas décadas, mais marcadamente a partir da década de 1990, oriundos das ciências cognitivas e das neurociências, da biologia molecular, da farmacologia da cognição, da própria genética, dentre outras ciências, vêm permitindo, entretanto, outras abordagens de compreensão do desenvolvimento do sistema nervoso, desafiando tal assunção. Dessa forma geram discussões e teorizações importantes para o entendimento mais aprofundado dos processos cognitivos e de aprendizagem envolvidos nas desordens do desenvolvimento e para as intervenções nesses processos.

As concepções de desenvolvimento, mormente em relação ao papel que a genética assume para a caracterização dos assim chamados "fenótipos" cognitivos e comportamentais - as características diferenciadas de aprendizagem, de emotividade, de afetividade, de expressão humoral, dentre outras, que estariam determinadas (ou não) pelo genótipo dos portadores de desordens de desenvolvimento - são definidoras das práticas interventivas educacionais e reabilitadoras. Considera-se que analisá-las, promovendo seu debate, crítica e apropriação teórica, é fundamental para impulsionar outra compreensão do sujeito portador de desordens de desenvolvimento e, assim, de sua educação e reabilitação.

Para tanto se trata, a seguir, das desordens de desenvolvimento de etiologia genética, de contraposições teóricas quanto à compreensão das desordens neurais de desenvolvimento e do impacto que essas concepções assumem para a compreensão do desenvolvimento cognitivo pré e pós-natal.

\section{As desordens neurais de desenvolvimento de etiologia genética}

O gene, a unidade hereditária celular básica, pode ser definido como sequências de nucleotídeos, também chamada de DNA (ácido 
desoxirribonucleico), responsáveis por codificar a síntese (ou a formação) de proteínas. Estas são essenciais para as funções estruturais do organismo, como a produção e regeneração dos tecidos, possuem função metabólica reguladora, exercendo ação enzimática (enzimas são proteínas), atuam na produção hormonal e no sistema imunológico (anticorpos são proteínas produzidas pelos linfócitos), além de outras. O DNA é essencial para a formação estrutural e a funcionalidade do sistema nervoso, pois codifica o número de proteínas que serão aí sintetizadas, e que cumprirão funções específicas, bem como a sua distribuição nos neurônios. Age, dentre outros, na formação e nas características anatômicas neuronais, no estabelecimento das sinapses e na qualidade dessas sinapses através da síntese de neurotransmissores, de seu transporte, recepção e reabsorção, e regulando o número e tamanho das vesículas que os contêm (CAREY, 2003).

As tentativas por se especificar as bases genéticas dos comportamentos "patológicos" das desordens neurológicas e psiquiátricas, de forma geral, vêm sendo um tópico de pesquisa prevalente - e também de constante embate - na História da Ciência. Sob o conceito de determinismo genético postula-se, desde os trabalhos de A. Weismann, em fins do século XIX, a concepção de que os genes determinam, por si só, características físicas, de personalidade, ou comportamentos. E, ainda que essa concepção venha sendo contestada, argumentando-se fortemente que a influência genética sobre o desenvolvimento e sobre o desenvolvimento do sistema nervoso é dependente da interação organismo/entorno, o debate continua.

A assunção principal a sustentar a posição do determinismo genético é a de que os genes contêm as informações que "programam" as potencialidades de desenvolvimento, desde o período embrionário. A contra-argumentação a essa assunção se dirige a afirmar que nem a influência genética se restringe às fases embrionárias, mas se apresentam em diversas outras fases do ciclo vital, sendo influenciadas por especificidades do período etário no qual o indivíduo se encontra, nem é absoluta. O impacto dessa influência está relacionada ao amalgamar-se de fatores de risco biológicos/ambientais, como mutações genéticas/ cromossômicas, resiliência de alelos específicos às mudanças no ambiente, exposição às agressões do meio, inclusive ao stress, dentre outros fatores.

O desenvolvimento humano transcorre através de um processo de relações dinâmicas envolvendo variáveis desde o nível biológico de organização àqueles socioculturais e históricos. Influências de todos os níveis genes, comportamento individual, práticas familiares na criação dos filhos, ou políticas sociais, por exemplo, contribuem integrativamente, e somente integrativamente, para a estrutura e função do comportamento e do desenvolvimento humano. Nenhum nível de organização, nenhum único conjunto de influências - seja ele genético ou cultural/ambiental - pode ser factualmente construído como um ímpeto exclusivo, ou mesmo pri- 
meiro, para o desenvolvimento completo de qualquer organismo. Nenhum dos dois sistemas funciona sem o outro. A adaptabilidade funcional e o fenótipo não são produtos de um único sistema isoladamente, mas de um concerto com os demais. (COLL, BEARER, LERNER, 2004, p. 226)

Mas e em relação às desordens neurais de desenvolvimento de etiologia genética, cujo fenótipo, no mais das vezes, se mostra tão aparentemente marcado, levando a generalizarem-se manifestações do comportamento individual como próprias a uma categoria sindrômica?

Estudos relatados por H. Tager-Flusberg $(1999,2005)$ mostram que explicações baseadas exclusivamente na causação genética não são suficientes para a compreensão da complexidade e diversidade dos quadros comportamentais, cognitivos, psicomotores e emocionais envolvidos nas desordens neurais de desenvolvimento, mesmo quando se referem a uma mesma síndrome ou patologia. A justificativa está nas variáveis interativas do próprio material genético em si e desse com as demais circunstâncias biológicas, sociais e ambientais do indivíduo. A exemplificação dessa variabilidade interativa, mais comumente encontrada na literatura especializada, trata da fenilcetonúria. ${ }^{1}$

Definida como um erro inato do metabolismo, que acarretaria numa desordem neural do desenvolvimento, a fenilcetonúria tem sido relacionada a uma falha na produção da enzima fenilalanina hidroxilase, originada de mutações alélicas nas bandas 22-24, do braço longo do cromossomo de número 12 (12q22-q24.1). Os mecanismos citopatológicos da fenilcetonúria já são bastante conhecidos e trata-se de um exemplo da variedade interativa genética tanto porque os efeitos pervasivos da expressão genética podem ser equilibrados por fatores ambientais - no caso uma dieta pobre em fenilalanina - como pelo grande número de mutações (entre 60-70) do gene associado à fenilcetonúria, refletindo-se em diversidade fenotípica (GOLDSTEIN; REYNOLDS, 1999; WAISBREN, 1999; TAGER-FLUSBERG, 1999). Ainda, não somente o mesmo gene relacionado à fenilcetonúria e suas mutações podem manifestar-se clinicamente sob diversas formas, como também há outras especificidades genéticas, que se manifestam como um quadro de fenilcetonúria, sem sê-lo, de fato. O risco de diagnósticos supergeneralizados para a fenilcetonúria, considerando-a como um quadro geneticamente único, leva ao risco de colocarem-se os "portadores" sob uma dieta de restrição à fenilalanina (um aminoácido essencial ao metabolismo corporal), com diversas consequências negativas. ${ }^{2}$

E se deve considerar que a fenilcetonúria é uma mutação mendeliana, ou seja, monogênica, estando associada a um único gene. Mas outras desordens genéticas apresentam mecanismos mais complexos, estando assim sujeitas a variabilidades interativas ainda maiores. Dentre essas estão aquelas relacionadas às alterações em um cromossomo inteiro (exemplos: Síndrome de Down, uma cópia extra do cromossomo 21, Síndrome de Edward, uma cópia a 
mais do cromossomo 18, Síndrome de Turner, uma cópia a menos do cromossomo $X$, ligado à expressão dos caracteres sexuais); à deleção, repetição, inversão ou translocação de segmentos de cromossomos (Síndrome de Angelman, Síndrome de Cri-du-Chat, por exemplo) ou às síndromes poligênicas, envolvendo alterações em diferentes genes (exemplos: a deleção do segmento de 11-13, no braço longo do cromossomo 15, na Síndrome de Prader-Willi, e algumas formas de autismo). ${ }^{3}$

Sem pretender negar o princípio de que o desenvolvimento neural e aquele dos processos cognitivos humanos são afetados por condições genéticas particulares, o que se argumenta aqui é se é possível correlacionar pontualmente certos genótipos - como aqueles das síndromes associadas a desordens neurais de desenvolvimento - a um determinado fenótipo cognitivo/ comportamental.

A confirmação dessa correlação exige o estabelecimento de uma relação de causa-efeito direta entre a "ação" genética e sua expressão fenotípica em um dado comportamento. Porém, frente à variabilidade genética e à variabilidade das interações gene/condições e história de vida individuais, como estabelecer essa relação de forma factível? Ainda, mesmo que uma correlação pontual possa ser estabelecida, como diferenciar se o "efeito" da condição genética estaria ocorrendo por uma influência genética "fraca" em algum sistema ou subsistema cerebral, ou pela total ausência de influência genética sobre esses sistema(s), ou ainda da somatória de influências recessivas, de um conjunto de genes, de forma mais dispersa sobre o sistema nervoso como um todo? ${ }^{4}$ Mais fundamentalmente, como diferenciar a ação genética sobre a geração de um fenótipo cognitivo/comportamental das próprias ações fisiológicas compensatórias, que um organismo efetua, diante de uma dada constituição genética? Isso exigiria a concepção de um organismo estático, organizacionalmente rígido, ou incapaz de reação por si próprio.

Essas questões estão no cerne de diferentes considerações teóricas sobre o processo de desenvolvimento e de desenvolvimento do sistema nervoso, a seguir discutidas.

\section{O processo de desenvolvimento: considerações epistemológicas}

Diferentes tendências e modelos teóricos da Biologia, da Psicologia e da Educação concebem o desenvolvimento como um movimento de mudança - provocada por um desdobrar de capacidades inatas ou de uma complexificação de capacidades mais simples - de um estágio a outro, em direção a um ponto diferentemente prefixado, em cada teoria, que seria aquele da maturidade do sujeito. Numa perspectiva que idealiza ser processual, a vivência de cada estágio é entendida como implicando um impacto permanente ou, ao menos duradouro, no estágio seguinte. Tais tendências, ou modelos teóricos, tendem a concentrar-se em características que seriam universais no desenvolvimento humano. Subjacente a essa perspectiva mantém-se a concepção de que o 
desenvolvimento do ser humano - e, por conseguinte, a expressão observável desse desenvolvimento, as ações e comportamentos dos indivíduos - pode ser previsto e influenciado ou direcionado.

\begin{abstract}
Infelizmente, muito da psicologia do desenvolvimento contemporânea e da neuropsicologia do desenvolvimento põe mais ênfase em padrões universais que emergem entre os indivíduos e pouca ênfase nos padrões individuais que o desenvolvimento segue. Modelos de estágios poderiam ser considerados um exemplo de uma ciência do desenvolvimento focada em processos unilineares e uniformes do desenvolvimento. (BERNINGER, ABBOTT, 2002, p. 302)
\end{abstract}

Nesse âmbito, a perspectiva neuropsicológica teoricamente identificada como clássica abrange modelos de compreensão dos processos psicológicos humanos que acompanham o "modelo médico", ou seja, procuram explicar os processos psicológicos "normais", a partir da análise das patologias que os obstaculizam. Parte de dois pressupostos centrais: há uma invariância no desenvolvimento do sistema nervoso, que seria fortemente determinado pelo desdobrar do "código genético" próprio à espécie, entendendo-se os desvios desse desdobramento padrão como decorrentes de erros nesse código genético ou por razões outras (traumas, agentes infecciosos, privações, etc.) e os processos psicológicos cognitivos decorrem da especialização funcional do córtex cerebral, hierarquicamente organizada em módulos, numa estrutura bottomup. Uma determinada disfunção nessa estrutura modular se refletiria na execução de performances cognitivas normais menos àquelas referentes às estruturas comprometidas pela disfunção (TEMPLE; CLAHSEN, 2002).

Essa ideia de "subtração" fundamenta a base metodológica da perspectiva neuropsicológica clássica: um modelo de desenvolvimento neuropsicomotor normal, determinado pela anatomia e fisiologia do sistema nervoso, do qual as patologias são, por reversão, reveladoras de desajustes. Em relação à cognição e às desordens de desenvolvimento genéticas, a perspectiva neuropsicológica clássica se dirige a indagar quais componentes do sistema nervoso estão danificados pela desordem cromossômica e quais se encontram preservados. A correlação entre o desenvolvimento patológico e os processos psicológicos "normais" se estabelece pela comparação de comportamentos entre crianças/crianças ou entre crianças/adultos normais e aqueles com comprometimento dos processos cognitivos, de base genética ou adquirida, através de testes padronizados, exames de neuroimagem, ou outros, post mortem.

Os procedimentos metodológicos para corroborar tal correlação são atualmente fonte de discussões e controvérsias. Algumas das críticas levantadas se referem: a) à inadequação de se correlacionar padrões diferenciados de desenvolvimento de base genética e outros, decorrentes de fatores ambientais, pois ambos teriam impacto diferenciado no desenvolvimento do sistema nervoso, b) à inadequação de se correlacionar o desempenho cognitivo de indivíduos 
adultos com aquele infantil, contestando assunções de que o desenvolvimento da criança recapitularia fielmente o desenvolvimento cognitivo próprio à espécie e c) a importância secundária que esses estudos atribuem aos fatores culturais como agentes influentes no desenvolvimento do sistema nervoso e, assim, dos processos cognitivos (MOLFESE; MOLFESE, 2002, DE HAAN; JOHNSON, 2002; THIES, 1985).

Contudo, a partir de 1990, acompanhando as intensas pesquisas sobre o sistema nervoso levadas a cabo naquela que ficou conhecida como a "Década do Cérebro", emergiram - ou se reafirmaram, concepções que entendem o desenvolvimento do sistema nervoso sob outra perspectiva.

As posições neuroconstrutivistas (MARESCHAL et al., 2007) e neuroconstrucionista (KARMILOFF-SMITH, 1995), guardando-se as respectivas diferenças de enfoque, representam algumas dessas perspectivas. Discordando de posições nativistas ${ }^{5}$ - que tendem a entender a organização cerebral cortical fundada em módulos especializados, tendo por base primordial o código genético, a influência ambiental sendo secundária, e de posições empiristas - que enfatizam o papel da experiência do indivíduo em seu entorno como o fator desencadeante da especialização cerebral, as posições construtivistas enfatizam a interdependência dinâmica entre estrutura/função e ambiente. A forma pela qual a organização cerebral, inclusive a cortical, se estrutura resulta, em última instância, dos mecanismos de desenvolvimento cerebral (indução neuronal, proliferação de neurônios e de células da glia, migração, morte e diferenciação celular, formação e "poda" sináptica), que são próprios à espécie humana, assim contidos em nosso código genético, mas cuja atividade é derivada das, ou imbricada às, diversas maneiras pelas quais os indivíduos interagem com o entorno. Atividade que se modifica conforme as próprias condições do entorno e do engajamento indivíduo-entorno também se modificam.

Em G. Westermann e colaboradores (2007, p. 80):

O neuroconstrutivismo vê o desenvolvimento desses sistemas neurais como pesadamente restringidos pela interação de múltiplos fatores, intrínsecos e extrínsecos ao desenvolvimento. O princípio central é a dependência do contexto. [...] A emergência das representações ${ }^{6}$ suportando comportamentos cognitivos é fortemente restringida pela história ontológica do indivíduo.

As perspectivas neuropsicológicas construtivistas enfatizam essa dinâmica entre o contexto (a história e as condições de vida do indivíduo) e o processo biológico de desenvolvimento do sistema nervoso e dos processos cognitivos. Negando que o sistema nervoso tenha um caráter inato especializado e modularmente organizado, determinado de acordo com as "instruções" do código genético, o desenvolvimento é compreendido como voltado ao engajamento bem-sucedido do indivíduo ao seu entorno. Do ponto de vista das desordens genéticas, isso significa assumir a concepção de que um fenótipo 
sindrômico, especialmente um "cognitivo e comportamental", não se constitui puramente como o resultado da manifestação de um erro cromossômico, mas são resultantes das especificidades dinâmicas desse desenvolvimento neural.

O distanciamento das assunções quanto à especialização modular inata do sistema nervoso abriu a possibilidade de pensar nos genes como influenciando não diretamente um determinado comportamento, mas a expressão de particularidades do desenvolvimento do sistema nervoso em seus microníveis moleculares e de organização estrutural e funcional mais básica: a velocidade e capacidade de mielinização, de crescimento e migração neural, de formação sináptica, da síntese de neurotransmissores, dentre outros. Tais alterações provocariam uma somatória de condições peculiares de desenvolvimento do sistema nervoso, que imbricadas às condições de vida que o indivíduo encontra, bem como a outras condições próprias do seu organismo (saúde geral, integridade das funções perceptivas...), afetariam todo o quadro do seu desenvolvimento globalmente. Ressalta-se que mesmo a expressão genômica nesses níveis mais básicos de estruturação e funcionamento do sistema nervoso é, ela própria, entendida como epigenética, ou seja, a manifestação dos genes reguladores dos processos, que ocorrem nesses níveis, também é entendida como influenciada pelas condições extrínsecas/intrínsecas ao indivíduo (KARMILOFF-SMITH, 2006).

Nesse âmbito o desenvolvimento é caracterizado como uma complexificação das capacidades e habilidades dos indivíduos que reflete - e é refletida - pela complexificação das funções neurais, que por sua vez estão coligadas à natureza das relações do indivíduo com o entorno, e não em virtude de uma maturação cerebral predominantemente predeterminada. O desenvolvimento humano é dependente da habilidade do indivíduo para aprender a partir das suas experiências com o entorno e ao emprego dessa aprendizagem para sustentar e possibilitar a tomada de decisões adaptativas, que são constantemente exigidas num entorno que se modifica continuamente. A qualidade do desenvolvimento neural e cognitivo está, assim, relacionada à qualidade das experiências e oportunidades de aprendizagem que o indivíduo encontra em seu viver.

Isso significa mudar o foco do processo de desenvolvimento sobre a carga genética em si para os fatores que podem influenciar a expressão dessa carga genética, que repercutirão na dinâmica formativa do sistema nervoso. Dentre esses fatores estão agentes químicos e físicos encontrados na materialidade do ambiente, os impulsos sensoriais e as relações socioafetivo-culturais. Uma ramificação dessa forma de conceber o desenvolvimento é a de que esse não seria o desabrochar de um resultante final previamente inscrito no material genético, mas seria, antes, o processo de regulação e adaptação dos microprocessos de formação do sistema nervoso enquanto esse se modifica - dentro dos parâmetros espécie-específicos, da interação entre os genes que compõem a carga genética do indivíduo e do processo de engajamento do indivíduo no entorno ao longo do seu ciclo vital. 
A importância que a perspectiva neuroconstrutivista atribui a ambos, à aprendizagem e à experiência do indivíduo em seu meio, como fatores de influência no curso do desenvolvimento, exige um olhar mais atento. Especialmente pela possibilidade de configurar-se como base teórica extremamente propícia para que nos mostremos mais sensíveis à percepção dos esforços e atitudes que o indivíduo assume para se integrar ao mundo, ações que se mostram particularmente delicada nos casos de desordens genéticas do desenvolvimentos. E, ainda, para pensarmos em formas de intervirmos mais adequadamente nessas ações, quer na sua educação quer na sua reabilitação ${ }^{7}$.

\section{Considerações finais}

A posição aqui considerada entende o desenvolvimento como processual, marcado por um caráter de plasticidade, dentro dos limites biológicos mais as possibilidades culturais do entorno; interação dinâmica que capacita o indivíduo a construir perspectivas de engajamento nas especificidades de suas circunstâncias, enquanto insere-se na teia de significados presentes nestas.

Tal assunção acompanha teorias que concebem o desenvolvimento humano não como uma sucessão contínua de estágios em direção a um aperfeiçoamento constante, até alcançar um ponto de maturidade ideal, mas como um processo que se desenrola, de maneira plástica, multimodal (cognitivo, biológico e sociocultural) e multidirecional (avanços e retrocessos), ao longo de todo o ciclo vital do indivíduo, da embriogênese à morte. Essas teorias defendem a ideia de que, embora haja padrões modais filogenéticos, que limitam a variação do desenvolvimento, há grande influência de fatores outros, que culminam na expressão de importantes diferenças individuais, ao longo do processo de desenvolvimento. Assim, enquanto a arquitetura básica dos comportamentos permanece filogeneticamente a mesma ao longo da vida, os padrões de organização dessa arquitetura se alteram devido a mudanças nos mecanismos fisiológicos de manutenção da auto-organização do sujeito, bem como nos suportes que esse encontra no ambiente e às expectativas sociais que o cercam. Reconhecem-se, nesse âmbito, três influências centrais para o desenvolvimento: 1) aquelas normativas, ligadas à ontogenia do sujeito, 2) aquelas normativas ligadas à história sociocultural de uma sociedade, que impactam a vida de diferentes coortes e gerações (guerras, epidemias, alterações climáticas profundas, crises econômicas, revoluções culturais...) e 3) aquelas não-normativas, eventos que podem atingir os indivíduos de maneira aleatória (BALTES, 1987; SCHAIE; WILLIS, 1978).

A concepção de que o desenvolvimento se estende ao longo de toda a vida do indivíduo, e de que esse não é um processo de contínuo progresso, mas que é marcado por avanços, retrocessos e descontinuidades, implica uma necessidade de estabelecer objetivos e práticas educacionais diferenciadas, visando contemplar as especificidades e necessidades de aprendizagem dos indivíduos ao longo da vida. 
Nesse sentido especial atenção deve ser dada à consideração de De Haan e Mark H. Johnson (2002, p. 09) quanto à plasticidade neural. Os autores argumentam que a ideia de que o sistema nervoso se desenvolve imbricadamente à natureza da experiência do indivíduo no entorno pode ser explicada pelo contactar que cada indivíduo faz com configurações do entorno que são comuns a todos os membros da espécie. Esse "solo comum", formado tanto por especificidades dos diferentes ambientes que a espécie humana habita como pela materialização das práticas socioculturais próprias à determinada coletividade, direcionaria a formação, a remodelação e a retenção de sinapses, de modo que o organismo melhor se habilitasse a responder/engajar-se ao seu entorno.

O organismo dos portadores de desordens neurais de desenvolvimento não é estático, nem determinado exclusivamente pela arquitetura de sua condição genética. Nem tampouco as pessoas portadoras de desordens neurais de desenvolvimento o são. Conceber seu processo de desenvolvimento como "aberto", fortemente coligado à qualidade das experiências de vida que lhes são possibilitadas e ao equilíbrio que conseguem alcançar dentro das suas circunstâncias, que se constituem no mundo como seres-de-desejo e não como objetos de práticas educacionais ou reabilitadoras que não reconhecem essa sua condição, é, na argumentação aqui discutida, essencial para alcançarmos outros patamares de compreensão dessas e de interação, interventiva ou não, para com essas pessoas.

\section{Referências}

BALTES, P. B. Theoretical Propositions of Life-Span Developmental Psychology: On the Dynamics Between Growth and Decline. Developmental Psychology, v. 2, n. 5, p. 611-626,1987.

BERNINGER, V. W.; ABBOTT, R. Modeling Developmental and Individual Variability in Reading and Writing Acquisition: A Developmental Neuropsychological Perspective. In: MOLFESE, D. L.; MOLFESE, V. J. (EDS). Developmental Variations in Learning: Applications to Social, Executive Function, Language, and Reading Skills. Mahwah, Lawrence Erlbaum Associates, 2002. p. 275- 308.

CAREY, G. Human Genetics for the Social Sciences. Sage Publications: London, 2003.

CICCHETTI, D. Development and Psycipathology. In: CICCHETTI, D.; COHEN, D. (EDS). Developmental Psycopathology: Theory and Method. v. 1. 2. ed. New Jersey: Wiley, 2006. p. 1-18.

COLL, C. T. G.; BEARER, E. L.; LERNER, R. M. Beyond Nature versus Nurture to More Complex, Relational and Dynamic Developmental Systems. In:

(EDS). Nature and Nurture: The Complex Interplay of Genetic and Environmental Influences on Human Behavior and Development. Lawrence Erlbaum Associates, 2004. p. 225-230. 
COMMITTEE On NERVOUS SYSTEM DISORDERS in DEVELOPING COUNTRIES. Institute of Medicine (IOM). Neurological, Psychiatric, and Developmental Disorders. Meeting the Challenge in the Developing World. Washington/D.C.: National Academic Press, 2001.

DE HAAN, M.; JOHNSON, M. H. Mechanisms and theories of brain development. In: _. (EDS). The Cognitive Science of Development. London: Psychology Press, 2002. p. 1-18.

FLINT, J. The genetic basis of cognition. Brain, Oxford Journals, v. 122, n. 11, p. 2015-2032, nov. 1999.

GENETICS HOME REFERENCE. [internet]. Bethesda (MD): National Library of Medicine (US), updated 2010 Jan. 31. Acesso em: 7 fev 2010. Disponível em: <http://ghr.nlm.nih.gov/>.

GENES AND DISEASE. [internet]. National Center for Biotechnology Information, Bethesda (MD): National Library of Medicine, 2007. Acesso em: 13 dez. 2009. Disponível em http: <//www.ncbi.nlm.nih.gov/>

GOLDSTEIN, S.; REYNOLDS, C. Basic Principles and Applications. In: (EDS). Handbook of Neurodevelopmental and Genetic Disorders in Children. New York: Guilford Press, 1999. p. 3-8.

HUNTERDON DEVELOPMENTAL CENTER. Medical Information on Developmental Disorders. Disponível no site do Huterdon Developmental Center, Division of Developmental Disabilities <http://www.state.nj.us/ humanservices/ddd/home/centers/hunterdon/>. Acesso em: 16 dez. 2009.

INSEL, T. R. Foreword for inaugural issue of Journal of Neurodevelopmental Disorders. Journal of Neurodevelopmental Disorders, n. 1, p. 2-3, 2009.

KAPLAN, J. The Limits and Lies of Human Genetic Research, Dangers for Social Policy. Routledge: New York, 2000.

KARMILOFF-SMITH, A. Beyond Modularity: A Developmental Perspective on Cognitive Science. Massachusetts: MIT Press, 1995.

Ontogeny, Genetics, and Evolution: A Perspective from Developmental Cognitive Neuroscience. Biological Theory, Konrad Lorenz Institute for Evolution and Cognition Research, 1(1), p. 44-51, 2006.

KARMILOFF-SMITH, A.; SCERIF, G.; THOMAS, M. Different Approaches to Relating Genotype to Fenotype in Developmental Disorders. Developmental Psychobiology, vol. 40, n. 3, p. 311-322, 2002.

MARESCHAL, D.; JOHNSON, M. H.; SIROIS, S.; SPRATLING, M.; THOMAS, M.; WESTERMANN, G. (EDS). Neuroconstructivism: How the Brain Constructs Cognition. v. 01, Oxford University Press, 2007. 
MOLFESE, D. L.; MOLFESE, V. J. Developmental Variations in Learning: Applications to Social, Executive Function, Language, and Reading Skills. Mahwah, Lawrence Erlbaum Associates, 2002.

SASTRE-RIBA, S. Condiciones tempranas del desarrollo y el aprendizaje: El papel de las funciones ejecutivas. Rev. Neurol, 42, (supl 2), p. S143-S151, 2006.

SCHAIE, L.; WILLIS, S. Life-span development: implications for Education. Review of Research in Education, v. 06, p. 120-156, 1978.

THIES, A. P. The Cognitive Neuroscience of Development. Review of Research in Education, v. 12, p. 91-119, 1985.

TAGER-FLUSBERG, H. An Introduction to Research on Neurodevelopmental Disorders from a Cognitive Neuroscience Perspective. In: Developmental Disorders. Massachusetts: MIT Press, 1999.

. What Neurodevelopmental Disorders Can Reveal about Cognitive Architecture: The Example of Theory of Mind. In: CARRUTHERS, Peter; LAURENCE, Stephen; STICH, Stephen. (EDS). The Innate Mind Structure and Contents. Oxford Scholarship, jul. 2005. p. 272-289.

TEMPLE, C.; CLAHSEN, H. How connectionist simulations fail to account for developmental disorders in children. Behavior and Brain Sciences, 25: 6, p. 769-770, 2002.

THOMAS, M. Developmental disorders of the language system. Lecture handout, Birkbeck/UCL, MSc Cognitive Neuropsychology, Disorders of Language, march, 19, 2009.

WAISBREN, S. Phenylketonuria. In: GOLDSTEIN, S.; REYNOLDS, C. (EDS). Handbook of Neurodevelopmental and Genetic Disorders in Children. New York: Guilford Press, 1999.

WESTERMANN, G.; MARESCHAL, D.; JOHNSON, M. H.; SIROIS, S.; SPRATLING, M.; THOMAS, M. Neuroconstructivism. Developmental Science, 10:1, p. 75-83, 2007.

Notas

1 Ver também A. Karmiloff-Smith, G. Scerif e M. Thomas (2002), Different Approaches to Relating Genotype to Fenotype in Developmental Disorders, para uma análise no caso da Síndrome do X-frágil.

2 Para uma análise mais estendida ver Kaplan, J. The Limits and Lies of Human Genetic Research, Dangers for Social Policy. 2000.

3 Ver Genetics Home Reference, 2010 e Genes and Disease, 2007. 
${ }^{4}$ Para outra análise ver Flint, Jonathan. The genetic basis of cognition, 1999.

${ }^{5}$ Ambos, o nativismo e o empirismo são teorias epistemológicas que se fundamentam na capacidade perceptiva: o nativismo parte do pressuposto que o conhecimento humano resulta da atividade perceptiva dos órgãos sensoriais, mais alguma base de conhecimento já existente, de forma inata; o empirismo defende que o conhecimento humano resulta da atividade perceptiva, advinda da experiência humana no entorno, mas sem uma base de conhecimento inata, previamente existente.

${ }^{6}$ Entendida pelos autores como a ativação, no cérebro, de padrões neurais que contribuem para comportamento adaptativo no meio. Portanto, compreender o desenvolvimento cognitivo requer uma compreensão de como os substratos neurais suportando as representações mentais são formados (WESTERMANN, et. al., 2007, p. 75).

${ }^{7}$ Ver, por exemplo, Sastre-riba, S. Condiciones tempranas del desarrollo y el aprendizaje: El papel de las funciones ejecutivas, 2006.

\section{Correspondência}

Maria Luísa Bissoto - Rua Prudente de Moraes, 1341, apto 172. CEP 13419-260, Piracicaba, São Paulo, Brasil.

E-mail: malubissoto@yahoo.com

Recebido em 25 de junho de 2010

Aprovado em 12 de dezembro de 2010 